\title{
Neighborhood greenspace exposure as a protective factor in dementia risk among U.S. adults 75 years or older: a cohort study
}

Erik D. Slawsky ${ }^{1}$ Anjum Hajat ${ }^{1 *}$, Isaac C. Rhew ${ }^{1}$, Helen Russette ${ }^{2}$, Erin O. Semmens ${ }^{3}$, Joel D. Kaufman', Cindy S. Leary ${ }^{3}$ and Annette L. Fitzpatrick ${ }^{1}$

\begin{abstract}
Background: Research suggests that greenspace may confer neurocognitive benefits. This study examines whether residential greenspace is associated with risk of dementia among older adults.

Methods: Greenspace exposure was computed for 3047 participants aged 75 years and older enrolled in the Gingko Evaluation of Memory Study (GEMS) across four U.S. sites that prospectively evaluated dementia and its subtypes, Alzheimer's disease (AD), vascular dementia (VaD), and mixed pathologies, using neuropsychiatric evaluations between 2000 and 2008. After geocoding participant residences at baseline, three greenspace metrics-Normalized Difference Vegetative Index, percent park overlap within a 2-km radius, and linear distance to nearest park - were combined to create a composite residential greenspace measure categorized into tertiles. Cox proportional hazards models estimated the associations between baseline greenspace and risk of incident all-cause dementia, AD, and Mixed/VaD.

Results: Compared to low residential greenspace, high residential greenspace was associated with a reduced risk of dementia ( $\mathrm{HR}=0.7695 \% \mathrm{Cl}: 0.59,0.98$ ) in models adjusted for multiple covariates. After additional adjustment for behavioral characteristics, Apolipoprotein E $\varepsilon 4$ status, and other covariates, the association was slightly attenuated $(\mathrm{HR}=0.82 ; 95 \% \mathrm{Cl}: 0.63,1.06)$. Those exposed to medium levels of greenspace also had $28 \%$ lower risk $(\mathrm{HR}=0.72 ; \mathrm{Cl}$ : $0.55,0.95)$ of dementia compared to those with low greenspace in adjusted models. Subtype associations between high residential greenspace and AD were not statistically significant. Greenspace was not found to be significantly associated with mixed/vascular pathologies.

Conclusions: This study showed evidence for an association between residential greenspace and all-cause dementia among older adults. Future research with larger sample size, precise characterization of different dementia subtypes, and assessment of residential greenspace earlier in life may help clarify the role between exposure to greenspace and dementia risk.
\end{abstract}

\footnotetext{
*Correspondence: Anjumh@uw.edu
}

${ }^{1}$ University of Washington, Seattle, WA, USA

Full list of author information is available at the end of the article permits use, sharing, adaptation, distribution and reproduction in any medium or format, as long as you give appropriate credit to the original author(s) and the source, provide a link to the Creative Commons licence, and indicate if changes were made. The images or other third party material in this article are included in the article's Creative Commons licence, unless indicated otherwise in a credit line to the material. If material is not included in the article's Creative Commons licence and your intended use is not permitted by statutory regulation or exceeds the permitted use, you will need to obtain permission directly from the copyright holder. To view a copy of this licence, visit http://creativecommons.org/licenses/by/4.0/. The Creative Commons Public Domain Dedication waiver (http://creativeco mmons.org/publicdomain/zero/1.0/) applies to the data made available in this article, unless otherwise stated in a credit line to the data. 


\section{Highlights}

- Residential greenspace exposure was found to be associated with moderate cognitive health benefit for older U.S. adults.

- Dementia subtypes may be differentially impacted by exposure to residential greenspace.

- Combining multiple greenspace measures may better capture a holistic picture of exposure to greenspace compared to one measure alone.

Keywords: Dementia, Greenspace, NDVI, Residential exposures, Alzheimer's disease

\section{Background}

Alzheimer's Disease and Related Dementias (ADRD) are estimated to globally cost over 2 trillion dollars by 2030 [1]. A recent study projected a two-fold increase in ADRD burden from $1.6 \%$ of the U.S. population in 2014 to $3.3 \%$ by 2060 with 13.9 million Americans suffering from ADRD [2]. It has been suggested that 35\% of dementia cases worldwide could be prevented by addressing modifiable risk factors, with $15 \%$ of cases addressable during later life ( $>65$ years) [3]. There has been increasing interest in exposure to greenspace as a possible modifiable protective factor because it may improve cognitive domains [4-6], reduce stress [7-9], increase physical exercise [10], improve social ties [11, 12] and mitigate air pollution [13-15].

As the mechanisms underlying dementia continue to be elucidated, it is becoming clear that chronic inflammation and stress play important roles in various dementia pathologies [16-18]. Greenspace as an exposure may play a role in preventing or mitigating such risk factors for dementia [19-21]. Studies have found greenspace exposure to be associated with healthier cortisol profiles $[22,23]$, which is a known biomarker for stress. Furthermore, greenspace may impact mental health and wellbeing more broadly [24-30]. Lastly, environments with abundant greenspace may promote physical activity which has been shown to reduce ADRD risk [31]. Yet, it is still unclear how exposure to greenspace influences risk of dementia among older adults, particularly risk of subtypes like vascular dementia (VaD), Alzheimer's disease (AD), and mixed pathologies. Examination of subtypes may aid in elucidating possible mechanisms of action (i.e. physical activity, pollution mitigation, stress reduction, social contact) for the greenspace-dementia relationship. Some research has already noted inverse associations between elevated greenspace exposure and $\mathrm{AD}$ using an ecological design [32].

This work aims to evaluate whether neighborhood greenspace is associated with reduced risk of incident dementia, including all-cause dementia and its subtypes of $\mathrm{AD}$ and Mixed/VaD, using a well characterized study of older adults evaluated for dementia over eight years.

\section{Methods \\ Study data}

The Ginkgo Evaluation of Memory Study (GEMS) was a double-blind, placebo controlled clinical trial developed to investigate the effect of Gingko biloba on dementia and its subtypes in older adults [33]. Participants were randomized using a block design to either twice-daily doses of $120 \mathrm{mg} \mathrm{G}$. biloba extract or an identical appearing placebo $[34,35]$. The original trial ran from 2000 to 2008 with more than 3000 participants from four sites: Winston-Salem, North Carolina; Hagerstown, Maryland; Pittsburgh, Pennsylvania; and Sacramento, California with a median follow-up time of 6.1 years. Participants were adults 75 years of age or older at baseline, did not have dementia at enrollment, and had provided a home address. Participants were assessed every six months for up to 8 years. Data were collected by physical examination, blood testing, and survey questionnaires. For our analysis 3069 participants had residential address information available; 22 of those addresses could not be geocoded bringing our sample to 3047 GEMS participants.

\section{Outcomes}

The classification of dementia was based on DSM-IV criteria [36]. Dementia due to AD was determined using criteria from the National Institute of Neurological and Communicative Disorders and Stroke/Alzheimer's Disease and Related Disorders Association (NINCDSADRDA) [37]. Dementia assessment was extremely robust in the GEMS trial, using a combination of Global Clinical Dementia Rating (CDR) [38], Alzheimer's Disease Assessment Scale (ADAS) [39], and Modified MiniMental State Exam (3MS) [40] to screen participants and a series of 12 neurophysiological tests in six domains to determine dementia and subtype status during follow-up [33]. Participants were administered this full neuropsychological battery at baseline. Every six months thereafter, all participants were re-assessed with the cognitive 
screening instruments to determine if the full battery of dementia assessments should be re-administered. For participants whose scores dropped a pre-specified number of points, dependent on individual participant baseline scores for two of the three tests (3MS CDR, or ADAS), the participant proxy reported new cognitive issues, a private physician diagnosed dementia, or the participant was prescribed a medication for dementia, the full battery was repeated. A blinded panel of experts consisting of two neurologists, two neuropsychologists, and one psychometrician reviewed results of the full battery. Participants were then classified as having dementia and its subtypes of $\mathrm{AD}$ only, $\mathrm{AD}$ and $\mathrm{VaD}$ (mixed), $\mathrm{VaD}$ only, or other type of dementia according to criteria from the NINCDS-ADRDA, National Institute of Neurological Disorders and Stroke-Association, Internationale pour le Recherche et l'Enseignement en Neurosciences, and the Alzheimer's Disease Diagnostic and Treatment Centers. Individuals were classified as either having dementia or not by end of study. In total, 523 cases of dementia occurred during the GEMS trial. Secondary analyses to evaluate $\mathrm{AD}$ only and Mixed/VaD dementia using criteria described above were also conducted. Of the sample with geocoded data, 518 cases of dementia were available for analysis.

\section{Greenspace measures}

Three data sources, the United States Geologic Survey Protected Areas Databases (USGS-PAD) as of 2018 [41], Trust for Public Land (ParkServe) as of 2018 [42], and eMODIS Normalized Difference Vegetation Index (NDVI) average for 2001 [43] were combined to create a composite metric for residential greenspace exposure. Each of these data sources define and measure greenspace exposure. USGS-PAD provides a standardized database for all federally recognized protected areas, which commonly includes parks and other forms of greenspaces that enable human-environment interaction. Smaller non-federally recognized greenspaces, like school yards and boulevards are captured by ParkServe. The combination of these two data sources yielded over 70,000 bounded areas across the four study cities. However, not all greenspaces are formally bounded areas, and thus NDVI can add critical information about the overall density of vegetation surrounding a residence regardless of cartographic boundaries. Seven-day composite summer values were used to provide an estimate of the maximum possible level of "greenness" to which a participant may have been exposed. Additionally, validation of NDVI as a neighborhood greenness measure was confirmed in a study that found a strong correlation with environmental psychologists' ratings of neighborhood greenness via photographs taken near residences to examine vegetative density [44], making NDVI a useful tool for assessing neighborhood greenness. Three essential measures were taken to determine a residence's level of greenspace exposure. First, linear distance from the residence to the nearest park centroid was recorded in meters $(\mathrm{m})$. Second, radial buffers were created out to $2 \mathrm{~km}$ from the residence in 500-m increments. The area of park overlap was then calculated for each buffer with cumulative totals calculated as a percent of the area of the buffer. Last, $250 \mathrm{~m}$ resolution NDVI pixel values were transformed to standardized -1 to 1 spectrum values, with values closer to 1 indicating more living vegetation. Mean values were calculated within the $2000 \mathrm{~m}$ buffer to create a single average NDVI value for each residence. These three measures were standardized as $\mathrm{z}$-scores with a mean of 0 and a standard deviation (SD) of 1 . Distance to the nearest park centroid was reverse coded so that larger values would be associated with closer access to park, just as larger values of NDVI and percent park overlap are also associated with more greenspace exposure. All measures were collected from the GEMS participant's address provided at baseline. The three standardized scores were then combined into a single composite greenness score by taking the average across all three standardized scores. Participants were then grouped into low, medium, and high greenspace based on percentile. Those with scores in the $33^{\text {rd }}$ percentile and below are classified as low exposure, 34th to 66th percentiles are classified as medium exposure, and those with scores in the 67th percentile and above are classified as high exposure. Utilizing a composite measure attempts to capture a more holistic picture of greenspace exposure. Sensitivity analyses were conducted to compare the composite measure the standardized single metrics (Supplemental Table 1).

\section{Covariates}

Selected covariates were included in the analysis to account for potential confounding and to test for effect modification. Demographic variables included age (in years) at randomization, sex (male or female), race (White, People of Color) as a social construct that may account for potential differences specific to race, treatment arm (G.biloba or placebo), and recruitment site (Winston-Salem, North Carolina; Hagerstown, Maryland; Pittsburgh, Pennsylvania; and Sacramento, California). Additional health behavior covariates included body mass index (BMI as a continuous scale), smoking status (measured by number of pack years, passive smoking percentage, and current smoking status defined as current former or never), alcohol consumption (number of drinks per week on average), and Assessment of Activities of Daily Life (ADL) mobility score which provides a standardized method of 
evaluating disability [45] by self-report questionnaire based on difficulty with specific mobility and strength related tasks. Lastly, we included Apolipoprotein E $\varepsilon 4$ (APOE ع4) genotype (i.e., presence of at least one copy of the $\varepsilon 4$ allele), and neighborhood socioeconomic status (NSES) scores where values under zero represent lower status and values above zero represent higher status. NSES was assessed with a similar index used in the Multi-Ethnic Study of Atherosclerosis [46] with values based on residential address at the census tract level. Principal components analysis of Census 2000 summary files and 2005-2009 American Community Survey indicated the following seven variables had the largest loadings and were used to construct NSES: $\%$ high school education, \% with Bachelor's degree, \% with managerial occupation, median home value, \% with interest/dividend/rental income, median household income, \% of households with income $>\$ 50,000$, and binary rurality assessed via Rural Urban Commuting Area codes of census tracts containing baseline addresses (codes of 3 or less is defined as urban and 4 to 10 are defined as rural) [47].

\section{Statistical analysis}

Analyses were conducted using R Version 4.0.1 [48] and QGIS 3.14 [49]. To estimate the association between greenspace and time until dementia diagnosis, Cox proportional hazards regression was used. Greenspace categories were included as dummy variables with low greenspace being the reference group. Covariates were added to regression models in a hierarchical fashion beginning with a minimally adjusted model and concluding in a fully adjusted model that included several behavioral risk factors and APOE $\varepsilon 4$ status. Model A adjusted for a minimal set of confounders: year, race, sex, treatment arm, and recruitment site. Model B further included NSES and education, as socioeconomic status (SES) is thought to confound the association between environmental exposures and health outcomes [50]. Model $\mathrm{C}$ added ADL mobility, MCI at baseline status, BMI, and APOE $\varepsilon 4$ status. Lastly, model D included a measure of rurality using rural-urban commuting codes to address possible urban/rural confounding. Cox models provide a flexible approach for assessing multiple predictors of right-censored time-to-event outcomes. Our models were run using Breslow's method of approximation for ties in the time data. We tested for the proportional hazards assumption using Schoenfeld residuals with all-cause dementia models $\mathrm{A}, \mathrm{B}, \mathrm{C}$, and D having global test $p$ values of $0.77,0.82,0.32$, and 0.36 respectively. Models assessing subtypes were run with the same covariate adjustment scheme listed above.

\section{Multiple imputation}

The allele status for APOE $\varepsilon 4$ is a strong risk factor for $\mathrm{AD}$ [51]. This is an important precision variable for analysis, but 615 (20.2\%) of the GEMS cohort were not tested for the gene. To account for missing APOE $\varepsilon 4$ status as well as missingness for all other study variables, we used Multiple Imputation by Chained Equations (mice) to impute missing APOE $\varepsilon 4$ and other study variable values [52]. Through the mice procedure, we generated 10 imputed datasets of missing observations for all variables. Models were run within each of the 10 datasets, and we pooled the parameter estimates and standard errors based on Rubin's rules [53].

\section{Results}

Our study sample consisted of 3047 participants. A total of 518 were classified with dementia over the course of the study. The GEMS cohort was predominantly White $(95 \%)$ and majority male (54\%). Mean age at baseline was 78.6 years (Table 1). Participants were spread across the four study sites with many participants receiving a college degree (23\%). Average BMI was $27.13 \mathrm{~kg} / \mathrm{m}^{2}$. Alcohol consumption was common among this sample with $74 \%$ reporting some form of weekly consumption. Our study sample, despite advanced age, was largely independently mobile (69\%). Additionally, $24 \%$ of those tested had the APOE $\varepsilon 4$ allele. Among dementia cases, Alzheimer's Disease (AD) was the most commonly identified subtype. Table 2 shows the distribution of greenspace metrics by exposure group as well as information on dementia subtypes.

As reflected in the Kaplan-Meier plot (Fig. 1) and the minimally adjusted Model A (Table 3), those living in high greenspace areas compared to low showed a $24 \%$ reduction in risk of dementia (Hazard Ratio $[\mathrm{HR}]=0.76$; 95\% CI: 0.59,0.97). These findings remained consistent in Model B after the addition of NSES and education $(\mathrm{HR}=0.76$; 95\% CI: $0.59,0.98)$. With the addition of all covariates in Model D, this association was attenuated and no longer statistically significant $(\mathrm{HR}=0.82 ; 95 \% \mathrm{CI}$ : $0.63,1.06)$ but still indicated a substantially lower point estimate. Medium greenspace exposure was consistent across all models and did remain statistically significant in Model D (HR $=0.77$; 95\% CI: 0.62,0.96).

Further analyses examined differential impact of greenspace exposure by dementia subtype (Table 3 ). In comparison to those with low greenspace, those with high greenspace exposure had a reported HR of 0.72 (CI: $0.46,1.13)$ for Mixed/VaD in Model A. Although the HR suggested a $28 \%$ reduction in risk, this association was not statistically significant and remained so after adjusting for additional covariates. For the 
Table 1 GEMS participant characteristics by greenspace exposure group presented as $\mathrm{n}$ and percent or mean and standard deviation

\begin{tabular}{|c|c|c|c|c|c|}
\hline & \multicolumn{5}{|c|}{ Greenspace Exposure Group ${ }^{a}$} \\
\hline & Low & Med & High & Total & $p$-value ${ }^{*}$ \\
\hline n (\%) & $1017(33)$ & $1014(33)$ & $1016(33)$ & 3047 & \\
\hline Age in years (mean (SD)) & $78.7(3.35)$ & $78.8(3.34)$ & $78.4(3.13)$ & $78.6(3.28)$ & 0.01 \\
\hline Dementia & $205(20.2)$ & $169(16.7)$ & $144(14.2)$ & $518(17.0)$ & $<0.01$ \\
\hline Race (\% self-identified White) & $964(94.8)$ & $972(95.9)$ & $972(95.7)$ & 2908 (95.4) & 0.47 \\
\hline Sex (\% male) & $552(54.3)$ & $534(52.7)$ & $550(54.1)$ & $1636(53.7)$ & 0.72 \\
\hline Recruitment site & & & & & $<0.01$ \\
\hline Winston-Salem, NC & $301(29.6)$ & $282(27.8)$ & $149(14.7)$ & $732(24.0)$ & \\
\hline Sacramento, CA & $527(51.8)$ & $295(29.1)$ & $81(8.0)$ & $903(29.6)$ & \\
\hline Hagerstown, MD & $75(7.4)$ & $224(22.1)$ & $148(14.6)$ & $447(14.7)$ & \\
\hline Pittsburg, PA & $114(11.2)$ & $213(21.0)$ & $638(62.8)$ & $965(31.7)$ & \\
\hline Treatment group (\% Ginkgo) & $519(51.0)$ & $513(50.6)$ & $498(49.1)$ & $1530(50.2)$ & 0.66 \\
\hline Education & & & & & 0.32 \\
\hline No high school diploma & $367(36.1)$ & $348(34.3)$ & $379(37.3)$ & $1094(35.9)$ & \\
\hline High school diploma & $269(26.5)$ & $265(26.1)$ & $236(23.2)$ & $770(25.3)$ & \\
\hline Some college & $146(14.4)$ & $159(15.7)$ & $175(17.2)$ & $480(15.8)$ & \\
\hline College graduate & $235(23.1)$ & $242(23.9)$ & $226(22.2)$ & $703(23.1)$ & \\
\hline BMI in $\mathrm{kg} / \mathrm{m}^{2}(\operatorname{mean}(\mathrm{SD}))$ & $27.2(4.24)$ & $27.1(4.24)$ & $27.1(4.40)$ & $27.1(4.29)$ & 0.98 \\
\hline Alcohol Consumption (mean(SD)) ${ }^{b}$ & $3.71(6.56)$ & $3.49(6.60)$ & $3.31(6.28)$ & $3.50(6.48)$ & 0.38 \\
\hline Smoking pack years (\%) & & & & & 0.34 \\
\hline 0 & $390(41.5)$ & $418(44.8)$ & $424(44.8)$ & $1232(43.7)$ & \\
\hline$>0-\leq 24$ & $289(30.7)$ & $265(28.4)$ & $254(26.8)$ & $808(28.7)$ & \\
\hline$>24$ & $261(27.8)$ & $250(26.8)$ & $268(28.3)$ & $779(27.6)$ & \\
\hline APOE $\varepsilon 4$ ( $\%$ allele present) & $186(23.8)$ & $198(24.4)$ & $189(22.5)$ & $573(23.6)$ & 0.64 \\
\hline ADL mobility (\% independent) & $700(68.9)$ & $689(67.9)$ & $702(69.1)$ & 2091 (68.6) & 0.39 \\
\hline $\mathrm{MCl}$ at baseline & $178(17.5)$ & $161(15.9)$ & $137(13.5)$ & $476(15.6)$ & 0.043 \\
\hline NSES (mean(SD)) & $0.70(3.15)$ & $-0.19(3.14)$ & $-0.61(3.10)$ & $-0.03(3.18)$ & $<0.01$ \\
\hline Rural $^{C}$ & $73(7.2)$ & $50(4.9)$ & $41(4.0)$ & $164(5.4)$ & $<0.01$ \\
\hline
\end{tabular}

Abbreviations: $A D L$ activities of daily life, $A P O E \& 4$ apolipoprotein $\mathrm{E} \varepsilon 4, B M I$ body mass index, $M C l$ mild cognitive impairment; NSES, neighborhood socioeconomic status

* $: P$-value reflects results from ANOVA/chi-square between greenspace exposure groups and covariate

a : Low: $\leq 33 \%$, Med:34-66\%, High: $\geq 67$

$\mathrm{b}:$ Average number of drinks per week

${ }^{c}$ : Binary rural based on Rural Urban Community Area codes

Alzheimer's disease subtype, those with medium greenspace exposure had $26 \%$ lower risk $(\mathrm{HR}=0.74$; CI: $0.56,0.97)$ compared to low greenspace in Model A. There was no statistically significant difference for the high greenspace exposure group in the fully adjusted model. Point estimates, however, indicate lower hazard ratios for all subtypes. Sensitivity analyses comparing the composite greenspace to standardized individual measures indicated that the composite measure produces stronger and more precise estimates for all cause dementia and Alzheimer's disease. NDVI is more strongly related to Mixed/VaD than the composite metric (Supplemental Table 1).

\section{Discussion}

This study evaluated associations between residential greenspace exposure and risk of dementia among older adults. By combining multiple spatial data sources, we were able to create a composite measure that captured multiple dimensions of greenspace and may better represent total greenspace exposure. Additionally, we applied this composite metric to a robust and well characterized cohort specifically designed to evaluate dementia and its subtypes. We observed protective associations between high greenspace exposure and all-cause dementia risk in models. After adjusting for socio-demographic covariates and further adjusting for additional behavioral 
Table 2 Greenspace exposure groups and dementia subtypes presented as $\mathrm{n}$ and percent or mean and standard deviation

\begin{tabular}{|c|c|c|c|c|c|}
\hline & \multicolumn{4}{|c|}{ Greenspace Exposure Group } & \multirow[b]{2}{*}{$\mathrm{p}^{*}$} \\
\hline & Low & Med & High & Total & \\
\hline $\mathrm{n}$ & 1017 & 1014 & 1016 & 3047 & \\
\hline Dementia (\%) & $205(20.2)$ & $169(16.7)$ & $144(14.2)$ & $518(17.0)$ & $<0.01$ \\
\hline AD only (\%) & $138(13.6)$ & $110(10.8)$ & $102(10.0)$ & $350(11.5)$ & 0.03 \\
\hline Mixed/VaD (\%) & $58(5.7)$ & $49(4.8)$ & $39(3.8)$ & $146(4.8)$ & 0.14 \\
\hline Mean (SD) & \multicolumn{4}{|c|}{ Greenspace Metrics } & \\
\hline Distance (m) & 1789 (2699) & $907(750)$ & $780(522)$ & $1159(1706)$ & $<0.01$ \\
\hline Mean percent Overlap & $0.94(1.47)$ & $1.49(2.26)$ & $6.69(11.05)$ & $3.04(7.06)$ & $<0.01$ \\
\hline NDVI & $0.46(0.11)$ & $0.57(0.08)$ & $0.68(0.09)$ & $0.57(0.13)$ & $<0.01$ \\
\hline Composite & $-0.26(0.71)$ & $0.12(0.31)$ & $0.38(0.53)$ & $0.00(0.60)$ & $<0.01$ \\
\hline
\end{tabular}

Abbreviations: $A D$ Alzheimer's disease, $m$ linear meters, NDVI normalized differences vegetative index, SD standard deviation, VaD Vascular dementia

${ }^{*}: P$-value reflects results from ANOVA/ chi-square between green space exposure group

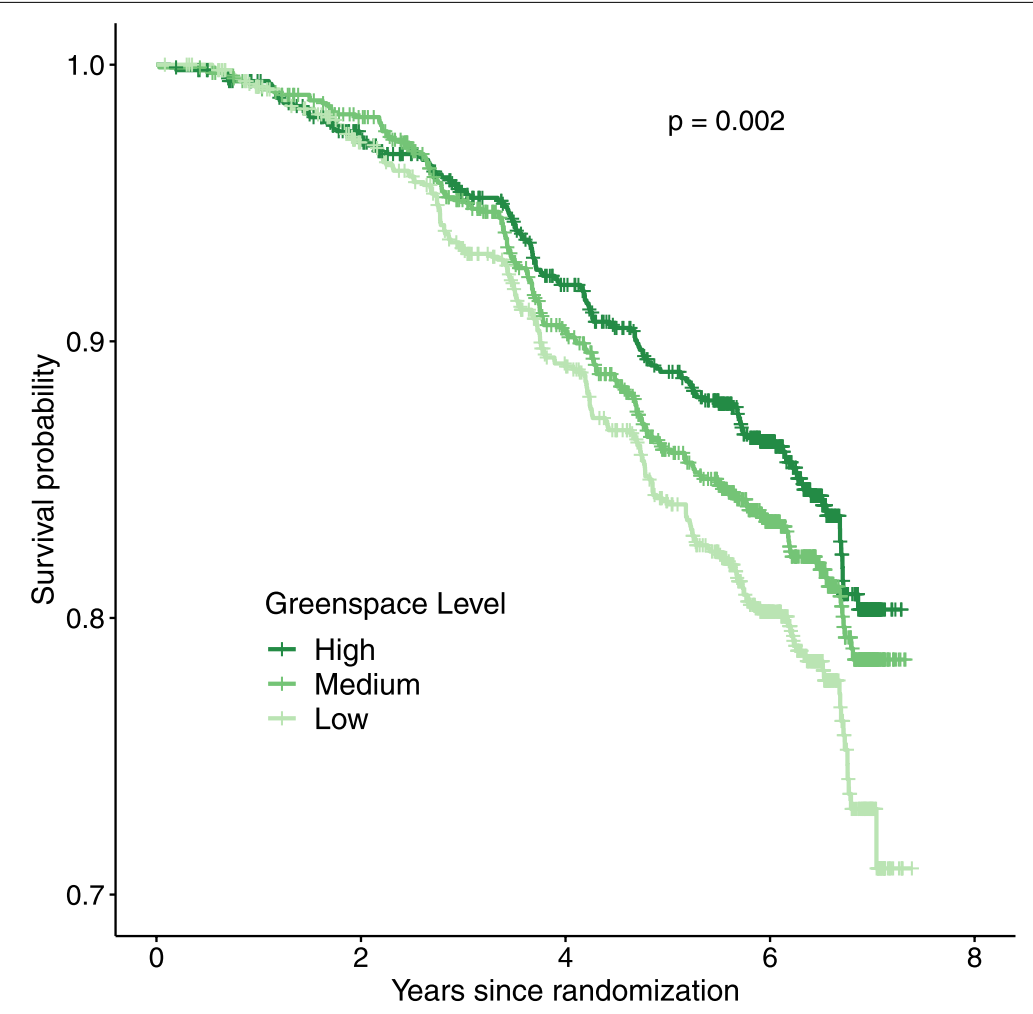

Fig. 1 Kaplan-Meier plot for dementia by residential greenspace group

characteristics, these associations were somewhat attenuated. Our results suggest that greenspace may offer protective benefits to those with medium to high residential exposure.

Results from this study appear to be generally consistent with other findings showing modest associations between greenspace and dementia outcomes [54-56]. Without more detailed information it is difficult to parse out whether mediation by physical exercise, air pollution mitigation, cognitive restoration, or increased socialization are the main route by which greenspace may be lowering risk or if it is a combination of many routes. Our high greenspace exposure group had the fewest dementia cases (Table 2), which might indicate the efficacy of greenspace for reducing dementia risk. A recent study from Canada which used a large national dataset found 
Table 3 Hazard ratios and 95\% confidence intervals from Cox proportional hazard models for association between composite greenspace exposure dementia and dementia subtypes with multiple imputation

\begin{tabular}{llll}
\hline \multicolumn{3}{c}{ Greenspace Exposure Group } \\
\cline { 2 - 4 } & Low & Med & High \\
\hline \multicolumn{3}{l}{ All-cause dementia } & \\
Model A & REF & $0.77(0.62,0.96)$ & $0.76(0.59,0.97)$ \\
Model B & REF & $0.77(0.62,0.96)$ & $0.76(0.59,0.98)$ \\
Model C & REF & $0.77(0.62,0.95)$ & $0.82(0.63,1.06)$ \\
Model D & REF & $0.77(0.62,0.96)$ & $0.82(0.63,1.06)$ \\
Mixed/VaD & & & \\
Model A & REF & $0.80(0.54,1.18)$ & $0.72(0.46,1.13)$ \\
Model B & REF & $0.83(0.56,1.24)$ & $0.77(0.48,1.23)$ \\
Model C & REF & $0.84(0.56,1.24)$ & $0.83(0.52,1.32)$ \\
Model D & REF & $0.84(0.56,1.24)$ & $0.83(0.52,1.33)$ \\
Alzheimer's Disease only & & \\
Model A & REF & $0.74(0.56,0.97)$ & $0.80(0.59,1.09)$ \\
Model B & REF & $0.72(0.55,0.94)$ & $0.78(0.57,1.06)$ \\
Model C & REF & $0.72(0.55,0.95)$ & $0.84(0.61,1.16)$ \\
Model D & REF & $0.73(0.56,0.96)$ & $0.84(0.61,1.16)$ \\
\hline
\end{tabular}

Model A: adjusted for year, race, sex, treatment arm, site

Model B: adjusted for Model A+NSES, education

Model C: adjusted for Model B + mobility, $\mathrm{MCl}$ at baseline, alcohol, smoking, APOE $\varepsilon 4, \mathrm{BMI}$

Model D: adjusted for Model C + rurality

statistically significant associations with urban greenspace exposure, dementia, and stroke [54]. Other studies have evaluated individual components of greenspace exposure, like NDVI, finding protective effects among older adults and Alzheimer's risk [57]. Using a large Medicare dataset, findings showed statistically significant but modest associations. Studies that evaluated greenspace exposure among a smaller sample often resulted in non-statistically significant findings [58, 59]. It was noteworthy that associations of medium greenspace exposure with dementia outcomes were similar or even sometimes stronger in magnitude than those of high greenspace exposure. This may, in part, reflect a maximum threshold of greenspace benefit. Beyond a certain level of greenness additional greenness may not confer added benefit, particularly for an older and less active population [60,61]. This is most apparent in the AD findings, where medium, but not high, greenspace exposure was significantly associated with all-cause dementia and AD.

While the mechanisms of various forms of dementia are still being elucidated, it is worth noting that greenspace may not influence each subtype of dementia in the same way. The Mixed/VaD subtypes may be more heavily influenced by exposures that impact cardiovascular health. While greenspace has been shown to mitigate the impacts of air pollution, further research is needed to determine if greenspace significantly alters air pollution effects for dementia outcomes [62]. Furthermore, countries with large national registries or insurance databases may add to our ability to study the relationship between greenspace and dementia [54]. Such future work may be warranted particularly considering research showing improvements in a variety of cognitive and physical outcomes is associated with individual and community-level interventions involving increasing greenspace exposure [63-67]. These promising interventions are perhaps the strongest evidence for the effects of greenspace exposure on dementia and cognitive outcomes.

Our study, like many greenspace studies, was limited in its ability to accurately identify and map greenspaces in which people may interact with the natural environment. This was partially ameliorated by the inclusion of several different sources of greenspace information but remains a perpetual concern. Further, we only assessed greenspace exposure at baseline, and could not account for additional features, amenities, safety, aesthetics, access, or other aspects that may impact space use. As a study of residential greenspace exposure there is also the possibility that the greenness around a residence does not reflect the level of exposure experienced by the participant as part of their routine activity spaces. Most of our sample was independently mobile $(68.6 \%)$, but mobility for the remainder of the sample and among older adults more generally, would limit time spent outdoors, this makes it difficult to measure physical activity mediated greenspace exposure. We also have no information on their exposure to greenspace earlier in life, which may have a larger impact on cognitive health than later life greenspace exposure [61] and rely on baseline addresses for determination of greenspace exposure. Additionally, the study sample may possibly be uniquely robust in their survival and absence of dementia at 75 , and thus not as readily susceptible to environmental influences on dementia risk. The lack of racial and economic diversity within our study population may be partly attributed to historical neighborhood discrimination. It is well characterized that residing in neighborhoods with no or low greenness is associated with increased risk of mortality among older adults $[68,69]$. Lastly, concerns of selection and generalizability exist due to the lack of racial, economic, and educational diversity in this sample. The GEMS sample was predominantly White, greatly reducing our ability to assess disparity in exposure and outcome and determine impacts from stressors related to lived experiences and racial discrimination [70]. Furthermore, the highly educated make-up of our sample has implications for generalizability given the importance of education in dementia development [71]. Our study 
benefitted from several strengths. Chief among them are the well characterized GEMS cohort, the robust dementia assessment, and the relatively long follow-up period. The multiple greenspace databases also allowed us to include over 70,000 bounded areas and when combined with NDVI create a more holistic picture of the greenspace exposure beyond parks/urban greenspace or vegetative cover alone.

Future greenspace research should focus on understanding which types of greenspace and what activities occur in them that may confer health benefits. This could involve modern data collection methodologies such as GPS-monitoring which has been utilized in some recent studies in order to capture exposure to greenspace beyond one's residential environment [21]. This type of study may assist in our understanding of potential mechanisms by which greenspace may be improving health including cognition. This study's findings may inform additional longitudinal analyses with the GEMS cohort to characterize specific subtypes of dementia and assess greenspace exposure at earlier times in the participant's life.

\section{Conclusions}

This study of residential greenspace exposure and dementia risk among older U.S. adults found evidence for protective associations between elevated greenspace exposure and incident dementia. Concerns over the aging U.S. population and possible interventions continue to grow. Larger and more robust investigations of how older adults interact with greenspaces may be warranted to accurately understand the role residential greenspace exposure plays in dementia risk among older adults.

\section{Supplementary Information}

The online version contains supplementary material available at https://doi. org/10.1186/s12940-022-00830-6.

Additional file 1: Supplemental Table 1. Hazard ratios and 95\% confidence intervals from Cox proportional hazard models for associations between composite greenspace exposure, standardized single greenspace exposure dementia and dementia subtype with multiple imputation.

\section{Acknowledgements}

GEMS participants and clinical trial research team.

\section{Authors' contributions}

Erik Slawsky: Conceptualization, Methodology, Software, Validation, Formal Analysis, Writing-Original Draft, Visualization; Annette Fitzpatrick: Conceptualization, Methodology, Writing- Review \& Editing, Supervision, Funding Acquisition; Isaac Rhew: Conceptualization, Methodology, Validation, WritingReview \& Editing, Supervision; Anjum Hajat: Conceptualization, Methodology, Validation, Writing- Review \& Editing, Supervision; Helen Russette: Writing- Review \& Editing; Erin Semmens: Writing- Review \& Editing, Funding Acquisition, Supervision; Joel Kaufman: Writing- Review \& Editing, Supervision, Funding Acquisition; Cindy Leary: Conceptualization, Methodology, Software,
}

Validation, Formal Analysis, Writing- Review \& Editing, Visualization, Supervision. All authors read and approved the final manuscript.

\section{Funding}

This study was supported by NIA/NIH (1RF1AG057033-01) and EPA (Star grant: RD831697). Data from the parent GEMS study was supported by grant U01 AT000162 from the National Center for Complementary and Alternative Medicine (NCCAM) and the Office of Dietary Supplements and National Institute on Aging; National Heart, Lung, and Blood Institute; University of Pittsburgh Alzheimer's Disease Research Center (P50AG05133); Roena Kulynych Center for Memory and Cognition Research; Wake Forest University School of Medicine; and National Institute of Neurological Disorders and Stroke. This research was also supported by the National Institute of General Medical Sciences of the National Institutes of Health (P20GM130418).

\section{Availability of data and materials}

Data collected for this analysis includes identifying information on participants, whose participation was confidential, and hence cannot be released in complete form. The study protocol, statistical analysis plan, and informed consent forms are available on request. De-identified data on the GEMS study, including a data dictionary, are available through the National Centralized Repository for Alzheimer's Disease and Related Dementias at ncrad.iu.edu.

\section{Declarations}

Ethics approval and consent to participate

The University of Washington Institutional Review Board approved this study. IRB ID: STUDY0006693.

\section{Consent for publication}

Not applicable.

\section{Competing interests}

The Author(s) declare that they have no competing interest.

\section{Author details}

${ }^{1}$ University of Washington, Seattle, WA, USA. ${ }^{2}$ Johns Hopkins University, Baltimore, MD, USA. ${ }^{3}$ University of Montana, Missoula, MT, USA.

Received: 24 September 2021 Accepted: 6 January 2022 Published online: 15 January 2022

References

1. Wimo A, Guerchet M, Ali GC, Wu YT, Prina AM, Winblad B, et al. The worldwide costs of dementia 2015 and comparisons with 2010. Alzheimers Dement. 2017:13(1):1-7.

2. Matthews KA, Xu W, Gaglioti AH, Holt JB, Croft JB, Mack D, et al. Racial and ethnic estimates of Alzheimer's disease and related dementias in the United States (2015-2060) in adults aged $\geq 65$ years. Alzheimers Dement. 2019;15(1):17-24

3. Livingston G, Sommerlad A, Orgeta V, Costafreda S, Huntley J, Ames D, et al. The lancet international commission on dementia prevention and care. Lancet. 2017;390:2673-734.

4. Barton J, Rogerson M. The importance of greenspace for mental health. BJPsych Int. 2017;14(4):79-81.

5. Kaplan R, Kaplan S. The experience of nature: a psychological perspective: CUP archive; 1989.

6. Plutchik R. A psychoevolutionary theory of emotions: Sage Publications; 1982.

7. van den Berg AE, Maas J, Verheij RA, Groenewegen PP. Green space as a buffer between stressful life events and health. Soc Sci Med. 2010;70(8):1203-10.

8. Felsten $\mathrm{G}$. Where to take a study break on the college campus: an attention restoration theory perspective. J Environ Psychol. 2009;29(1):160-7.

9. Barton J, Hine R, Pretty J. The health benefits of walking in greenspaces of high natural and heritage value. J Integr Environ Sci. 2009:6(4):261-78. 
10. Richardson EA, Pearce J, Mitchell R, Kingham S. Role of physical activity in the relationship between urban green space and health. Public Health. 2013;127(4):318-24

11. Fratiglioni L, Paillard-Borg S, Winblad B. An active and socially integrated lifestyle in late life might protect against dementia. Lancet Neurol. 2004;3(6):343-53.

12. Holtan MT, Dieterlen SL, Sullivan WC. Social life under cover: tree canopy and social capital in Baltimore. Maryland Environ Behav. 2015:47(5):502-25.

13. Maas J, Verheij RA, de Vries S, Spreeuwenberg P, Schellevis FG, Groenewegen PP. Morbidity is related to a green living environment. J Epidemiol Commun Health. 2009;63(12):967-73.

14. Rückerl R, Schneider A, Breitner S, Cyrys J, Peters A. Health effects of particulate air pollution: a review of epidemiological evidence. Inhal Toxicol. 2011;23(10):555-92.

15. Oudin A, Forsberg B, Adolfsson AN, Lind N, Modig L, Nordin M, et al. Traffic-related air pollution and dementia incidence in northern Sweden: a longitudinal study. Environ Health Perspect. 2016;124(3):306-12.

16. Miklossy J. Chronic inflammation and Amyloidogenesis in Alzheimer's disease--role of spirochetes 1. J Alzheimers Dis. 2008;13(4):381-91.

17. Peavy GM, Jacobson MW, Salmon DP, Gamst AC, Patterson TL, Goldman $S$, et al. The influence of chronic stress on dementia-related diagnostic change in older adults. Alzheimer Dis Assoc Disord. 2012;26(3):260.

18. Leonard BE. Inflammation, depression and dementia: are they connected? Neurochem Res. 2007;32(10):1749-56.

19. Dadvand P, Nieuwenhuijsen M. Green space and health. In: Integrating human health into urban and transport planning: Springer; 2019. p. 409-23.

20. Groenewegen PP, Van den Berg AE, De Vries S, Verheij RA. Vitamin G: effects of green space on health, well-being, and social safety. BMC Public Health. 2006:6(1):1-9.

21. Mennis J, Mason M, Ambrus A. Urban greenspace is associated with reduced psychological stress among adolescents: a geographic ecological momentary assessment (GEMA) analysis of activity space. Landsc Urban Plan. 2018:174:1-9.

22. Roe JJ, Thompson CW, Aspinall PA, Brewer MJ, Duff El, Miller D, et al. Green space and stress: evidence from cortisol measures in deprived urban communities. Int J Environ Res Public Health. 2013;10(9):4086-103.

23. Thompson CW, Roe J, Aspinall P, Mitchell R, Clow A, Miller D. More green space is linked to less stress in deprived communities: evidence from salivary cortisol patterns. Landsc Urban Plan. 2012;105(3):221-9.

24. de Keijzer C, Gascon M, Nieuwenhuijsen MJ, Dadvand P. Long-term green space exposure and cognition across the life course: a systematic review. Curr Environ Health Rep. 2016;3(4):468-77.

25. Takano T, Nakamura K, Watanabe M. Urban residential environments and senior citizens' longevity in megacity areas: the importance of walkable green spaces. J Epidemiol Commun Health. 2002:56(12):913-8.

26. Engemann K, Pedersen CB, Arge L, Tsirogiannis C, Mortensen PB, Svenning J-C. Residential green space in childhood is associated with lower risk of psychiatric disorders from adolescence into adulthood. Proc Natl Acad Sci. 2019:116(11):5188-93.

27. Lee AC, Maheswaran R. The health benefits of urban green spaces: a review of the evidence. J Public Health. 2011;33(2):212-22.

28. Nieuwenhuijsen MJ, Gascon M, Martinez D, Ponjoan A, Blanch J, GarciaGil MM, et al. Air pollution, noise, blue space, and green space and premature mortality in Barcelona: a mega cohort. Int J Environ Res Public Health. 2018;15(11):2405.

29. Sugiyama T, Leslie E, Giles-Corti B, Owen N. Associations of neighbourhood greenness with physical and mental health: do walking, socia coherence and local social interaction explain the relationships? J Epidemiol Commun Health. 2008;62(5):e9.

30. Cohen-Cline H, Turkheimer E, Duncan GE. Access to green space, physical activity and mental health: a twin study. Epidemiol Commun Health. 2015;69(6):523-9.

31. Besser L. Outdoor green space exposure and brain health measures related to Alzheimer's disease: a rapid review. BMJ Open. 2021;11(5):e043456.

32. Wu J, Jackson L. Greenspace inversely associated with the risk of Alzheimer's disease in the mid-Atlantic United States. Earth. 2021:2(1):140-50.
33. DeKosky ST, Williamson JD, Fitzpatrick AL, Kronmal RA, Ives DG, Saxton JA, et al. Ginkgo biloba for prevention of dementia: a randomized controlled trial. JAMA. 2008:300(19):2253-62.

34. DeKosky ST, Fitzpatrick A, Ives DG, Saxton J, Williamson J, Lopez OL, et al. The Ginkgo evaluation of memory (GEM) study: design and baseline data of a randomized trial of Ginkgo biloba extract in prevention of dementia. Contemp Clin Trials. 2006;27(3):238-53.

35. Fitzpatrick AL, Fried LP, Williamson J, Crowley P, Posey D, Kwong L, et al. Recruitment of the elderly into a pharmacologic prevention trial: the Ginkgo evaluation of memory study experience. Contemp Clin Trials. 2006;27(6):541-53.

36. Association AP. Diagnostic and statistical manu al of mental disorders. Washington, DC: American Psychiatrie Publishing; 1994.

37. McKhann G, Drachman D, Folstein M, Katzman R, Price D, Stadlan EM Clinical diagnosis of Alzheimer's disease: Report of the NINCDS-ADRDA Work Group* under the auspices of Department of Health and Human Services Task Force on Alzheimer's Disease. Neurology. 1984;34(7):939.

38. Morris JC. Clinical dementia rating: a reliable and valid diagnostic and staging measure for dementia of the Alzheimer type. Int Psychogeriatr. 1997;9(S1):173-6.

39. Weyer G, Erzigkeit H, Kanowski S, Ihl R, Hadler D. Alzheimer's disease assessment scale: reliability and validity in a multicenter clinical trial. Int Psychogeriatr. 1997;9(2):123-38.

40. McDowell I, Kristjansson B, Hill G, Hebert R. Community screening for dementia: the mini mental state exam (MMSE) and modified mini-mental state exam (3MS) compared. J Clin Epidemiol. 1997;50(4):377-83.

41. U.S. Geological Survey (USGS) Gap Analysis Project (GAP). Protected Areas Database of the United States (PAD-US) 2.1: U.S. Geological Survey data release. 2020. https://doi.org/10.5066/P92QM3NT.

42. The Trust for Public Land ParkServe ${ }^{\circledR}$. ParkServe ${ }^{\circledR}$ Data Downloads. 2019. Available from: https://www.tpl.org/parkserve/downloads.

43. Jenkerson CB, Maiersperger T, Schmidt G. eMODIS: A user-friendly data source: U.S. Geological Survey Open-File Report 2010-1055. 2010. p. 10.

44. Rhew IC, Vander Stoep A, Kearney A, Smith NL, Dunbar MD. Validation of the normalized difference vegetation index as a measure of neighborhood greenness. Ann Epidemiol. 2011;21(12):946-52.

45. Katz S, Ford A, Moskowitch R, Jackson B, Jaffe M. Studies of illness in the aged The index of ADL: a standardized measure of biological and psychosocial function. JAMA. 1963;21:914-9.

46. Christine PJ, Auchincloss AH, Bertoni AG, Carnethon MR, Sánchez BN, Moore K, et al. Longitudinal associations between neighborhood physical and social environments and incident type 2 diabetes mellitus: the multi-ethnic study of atherosclerosis (MESA). JAMA Intern Med. 2015;175(8):1311-20.

47. Cromartie J. 2010 Rural-Urban Commuting Area (RUCA) Codes: USDA; 2020 [Available from: https://www.ers.usda.gov/data-products/ruralurban-commuting-area-codes/documentation/.

48. R Core Team. R: A language and environment for statistical computing. Vienna: R Foundation for Statistical Computing; 2019. https://www.Rproject.org/.

49. QGIS.org. QGIS Geographic Information System. QGIS Association. 2019. http://www.qgis.org.

50. Hajat A, MacLehose RF, Rosofsky A, Walker KD, Clougherty JE. Confounding by socioeconomic status in epidemiological studies of air pollution and health: challenges and opportunities. Environ Health Perspect. 2021;129(6):65001.

51. Sanan DA, Weisgraber KH, Russell SJ, Mahley RW. Huang D, Saunders a, et al. apolipoprotein E associates with beta amyloid peptide of Alzheimer's disease to form novel monofibrils. Isoform apoE4 associates more efficiently than apoE3. J Clin Invest. 1994;94(2):860-9.

52. van Buuren S, Groothuis-Oudshoorn K. mice: Multivariate Imputation by Chained Equations in R. J Stat Softw. 2011;45(3):1-67. https://doi.org/10. 18637/jss.v045.i03.

53. Rubin DB. Multiple imputation for nonresponse in surveys: John Wiley \& Sons; 2004

54. Paul LA, Hystad P, Burnett RT, Kwong JC, Crouse DL, van Donkelaar A, et al. Urban green space and the risks of dementia and stroke. Environ Res. 2020;186:109520.

55. Astell-Burt T, Navakatikyan MA, Feng X. Urban green space, tree canopy and 11-year risk of dementia in a cohort of 109,688 Australians. Environ Int. 2020;145:106102. 
56. Besser LM, Lovasi GS, Michael YL, Garg P, Hirsch JA, Siscovick D, Hurvitz P, Biggs ML, Galvin JE, Bartz TM, Longstreth WT. Associations between neighborhood greenspace and brain imaging measures in nondemented older adults: the Cardiovascular Health Study. Soc Psychiatry Psychiatr Epidemiol. 2021;56(9):1575-85. https://doi.org/10.1007/s00127020-02000-w. Epub 2021 Jan 3.

57. Brown SC, Perrino T, Lombard J, Wang K, Toro M, Rundek T, et al. Health disparities in the relationship of neighborhood greenness to mental health outcomes in 249,405 US Medicare beneficiaries. Int J Environ Res Public Health. 2018;15(3):430.

58. Yitshak-Sade M, Kloog I, Novack V. Do air pollution and neighborhood greenness exposures improve the predicted cardiovascular risk? Environ Int. 2017;107:147-53.

59. Potestio ML, Patel AB, Powell CD, McNeil DA, Jacobson RD, McLaren L. Is there an association between spatial access to parks/green space and childhood overweight/obesity in Calgary, Canada? Int J Behav Nutr Phys Act. 2009;6(1):77.

60. Russo A, Cirella GT. Modern compact cities: how much greenery do we need? Int J Environ Res Public Health. 2018;15(10):2180.

61. Kabisch N, van den Bosch M, Lafortezza R. The health benefits of naturebased solutions to urbanization challenges for children and the elderly - a systematic review. Environ Res. 2017;159:362-73.

62. Baldauf R. Chapter 17 - air pollution mitigation through vegetation barriers and green space. In: Khreis H, Nieuwenhuijsen M, Zietsman J, Ramani T, editors. Traffic-Related Air Pollution: Elsevier; 2020. p. 437-53.

63. Russell KC. What is wilderness therapy? J Exp Educ. 2001;24(2):70-9.

64. Branas CC, Cheney RA, MacDonald JM, Tam VW, Jackson TD, Ten Have TR. A difference-in-differences analysis of health, safety, and greening vacant urban space. Am J Epidemiol. 2011;174(11):1296-306.

65. South EC, Hohl BC, Kondo MC, MacDonald JM, Branas CC. Effect of greening vacant land on mental health of community-dwelling adults: a cluster randomized trial. JAMA Netw Open. 2018;1 (3):e180298.

66. White PC, Wyatt J, Chalfont G, Bland JM, Neale C, Trepel D, et al. Exposure to nature gardens has time-dependent associations with mood improvements for people with mid-and late-stage dementia: innovative practice. Dementia. 2018;17(5):627-34.

67. McCallum J, Simons LA, Simons J, Friedlander Y. Delaying dementia and nursing home placement: the Dubbo study of elderly Australians over a 14-year follow-up. Ann NY Acad Sci. 2007;1114(1):121-9.

68. Bauwelinck M, Casas L, Nawrot TS, Nemery B, Trabelsi S, Thomas I, et al. Residing in urban areas with higher green space is associated with lower mortality risk: a census-based cohort study with ten years of follow-up. Environ Int. 2021;148:106365.

69. Gronlund CJ, Berrocal VJ, White-Newsome JL, Conlon KC, O'Neill MS. Vulnerability to extreme heat by socio-demographic characteristics and area green space among the elderly in Michigan, 1990-2007. Environ Res. 2015;136:449-61.

70. Ward JB, Gartner DR, Keyes KM, Fliss MD, McClure ES, Robinson WR. How do we assess a racial disparity in health? Distribution, interaction, and interpretation in epidemiological studies. Ann Epidemiol. 2019;29:1-7.

71. Sharp ES, Gatz M. The relationship between education and dementia an updated systematic review. Alzheimer Dis Assoc Disord. 2011;25(4):289.

\section{Publisher's Note}

Springer Nature remains neutral with regard to jurisdictional claims in published maps and institutional affiliations.

Ready to submit your research? Choose BMC and benefit from:

- fast, convenient online submission

- thorough peer review by experienced researchers in your field

- rapid publication on acceptance

- support for research data, including large and complex data types

- gold Open Access which fosters wider collaboration and increased citations

- maximum visibility for your research: over $100 \mathrm{M}$ website views per year

At BMC, research is always in progress.

Learn more biomedcentral.com/submissions 